\title{
Muscular Pre-Activation with Calistic Exercises Can Improve Strength Resistance and Maximum Repetition (1 rm) in Trained Men
}

\author{
Júlio César Barboza Scarcella ${ }^{1}$, Marcus Vinicius de Almeida Campos ${ }^{1}$, Marcelo Francisco Rodrigues ${ }^{2}$, Rafael \\ Dramis Calixto ${ }^{3}$ and Henrique Miguel $^{2,3 *}$
}

1Department of Physical Education, Euclides da Cunha College, Brazil

2Department of Physical Education, Espirito Santo do Pinhal University Regional Center, Brazil

3Department of Physical Education, Machado Higher Education and Research Center, Brazil

Submission: May 06, 2019; Published: May 15, 2019

*Corresponding author: Henrique Miguel, Department of Physical Education, Machado Higher Education and Research Center, Brazil

\begin{abstract}
Introduction: Strength training (ST) is structured according to the combination of variables such as: number of exercises, sets, repetitions and loads, execution speed, recovery interval and exercise order. The practice of calisthenics exercises is summarized in the use of one's own body weight, requiring strength, coordination and balance. Basically, they are body lifting exercises in bars or arm pushups in the ground.

Objective: The aim of this study is to verify if a set with calisthenic exercise performed until fatigue, before a traditional pectoralis training (using the bench press) can promote differences in strength resistance (maximum number of repetitions with 50\% of 1 RM) and a maximum repetition (1RM).

Methodology: Twelve healthy trained subjects (22.8 \pm 2.3 years) divided into traditional group (GT) and fatigued group (GF) participated in this study. The protocol was performed for 12 weeks and was defined by 10 sets of bench press with 75\% of 1RM and interval of 80 seconds. The GF still performed a pre-exhaustive series of arm flexion until fatigue before the defined protocol. The loading of $1 \mathrm{RM}$ and the maximum repetitions amount to $50 \%$ of $1 \mathrm{RM}$ were evaluated at the pre and post protocol moments.

Results: The results were statistically significant increase in GF for both $1 \mathrm{RM}(\mathrm{p}<0.05)$ and maximal repetitions with $50 \%$ of $1 \mathrm{RM}(\mathrm{p}=$ 0.0001), in relation to GT.

Conclusion: Thus, the present study showed that a series of calisthenics exercises performed until fatigue, preceding the traditional training of pectorals, using the bench press exercise, can be a good strategy to increase strength resistance (maximum number of repetitions with $50 \%$ of $1 \mathrm{RM}$ ) and at maximum 1RM strength.
\end{abstract}

Keywords: Bodybuilding, Strength training, Concentric fatigue, calisthenics, strength endurance

\section{Introduction}

Currently, individuals who train with weights have sought more effective training methods when the goal is to optimize sports performance Nunes, Rosa, Vecchio [1]. Strength training (TF) is one of the exercises most practiced by both athletes seeking physical fitness improvement and individuals who wish to improve their physical form Rosa [2]. Also known as training with weights or loads, this type of training has not only been indicated for the promotion of muscular strength, potency, resistance or hypertrophy; has been highlighted as an essential component in the prevention and treatment of cardiovascular diseases, since low levels of muscular strength are associated with the prevalence of obesity, metabolic syndrome and arterial hypertension Tibal [3], Miguel [4], Miguel [5]. The practice of calisthenics exercises is summarized in the use of one's own body weight, requiring strength, coordination and balance. Basically, they are body lifting exercises on bars or arm pushups in the ground Inácio [6]. The ability of a muscle or muscle group to exert tension against a resistance is called force, and the individual can overcome it, sustain it, or yield to it. The force action can be of the tough, fast or maximum type. The increase in maximum strength results in a lower relative load in day-to-day activities and, consequently, lower physiological stress Bacarin [7]. 
Fatigue, on the other hand, occurs when there is a decrease in the capacity of repetition of a certain force of contraction and power, in prolonged exercises. It can be classified in muscular fatigue and chronic fatigue, being that in the first the musculature has its potential of reduced response to stimuli, being localized, painful and acute; already in the second, occurs in a generalized manner, and may be a reflection of long periods of activity, inadequate nutrition and rest time, lack of motivation, etc. Caliani, Murata, Rocha [8]. The result of the combination of factors that make up the neuromuscular system, such as the length-tension relationship of the sarcomere, loadvelocity, force, time, and the construction of skeletal muscle, will produce muscle strength; where their gain will occur according to the neural and morphological adaptations that take place during the training Paz [9], Geraldes [10]. The generation of muscular strength is related to the intensity of the training routine. The tension produced in the muscle during training is what contributes to the force gain rather than the number of repetitions Rosa [2]. The ST (Strength Training) is structured according to the combination of variables such as: number of exercises, series, repetitions and loads, execution speed, recovery interval and exercise order. Generally, TF programs mobilize large muscle groups before the smallest groups, in order to provide greater training stimulus for all muscles involved in exercise, since a superior stimulus is provided, due to a greater neural, metabolic, hormonal and circulatory response. In short, structural and multi-articular exercises are performed before monoarticulate exercises, because this way we can use larger loads, since the fatigue is limited, and the smaller muscle groups fatigue faster than the larger groups Tibana, Balsamo, Prestes [3], Rosa [2].

The literature also suggests the use of isolated exercises that employ the small muscle groups before the large groups, such as the execution of the extensor muscles of the knee before the leg press. This training method is known as pre-exhaustion Tibana, Balsamo, Prestes [3]. Pre-exhaustion is an ST model where there is manipulation in the order of execution of two ST exercises, that is, a monoarticular exercise is followed first, followed by a multiarticular, where both mobilize at least one muscle or muscle group as agonist of both exercises Geraldes [10]. This method is based on the theoretical assumption that, when performing an exercise involving several joints, the small muscle groups will fatigue before the large muscles can be induced to the limit of their working capacity Tibana, Balsamo, Prestes [3]. Certain methods of working in bodybuilding seek that an exercise may cause fatigue in a particular muscle / muscle group, which acts as an agonist in the two subsequent exercises of the training session, thus providing greater muscle / muscle group demand that is emphasized in multi-joint exercise and a lower request of muscle / muscle group pre-exhaustion Geraldes [10]. Therefore, the aim of this work is to verify if a series with calisthenic exercise performed until fatigue, before a traditional pectoral training (using the bench press) can promote differences in strength resistance (maximum number of repetitions with $50 \%$ of $1 \mathrm{RM}$ ) and a maximum repetition (1RM).

\section{Methodology}

\section{Sample}

The sample for this study was composed of 12 trained healthy men, with time of practice of bodybuilding over 2 years. The individuals were voluntarily selected, where they showed interest in the research and were in agreement with all the procedures performed during the period of the research. All the subjects signed the Informed Consent Term (TCLE) and the methodology used was elaborated respecting the resolutions 196/96 of the National Health Council (Table 1).

Table 1: Sample definition.

\begin{tabular}{|c|c|c|}
\hline & GT & GSF \\
\hline Age (years) & $22,5 \pm 2,4$ & $23,2 \pm 2,2$ \\
\hline Weight (kg) & $78,1 \pm 1,8$ & $79,7 \pm 2,2$ \\
\hline IMC & $24,8 \pm 0,9$ & $25,4 \pm 1,2$ \\
\hline 1RM & $79 \pm 3,28$ & $78,6 \pm 4,84$ \\
\hline Training Experince (years) & $2,3 \pm 0,2$ & $2,4 \pm 04$ \\
\hline
\end{tabular}

\section{Experimental Draw}

The moments of the research were divided into three stages that will be described for a better understanding of the experimental design.

$\mathbf{1}^{\text {st }}$ Stage: After selecting the 12 individuals, they underwent 1RM evaluation and muscular strength endurance evaluation (maximum number of repetitions with $50 \%$ of $1 \mathrm{RM}$ ). After this, randomly, they were divided into two groups: Traditional training group (GT) and Group training sets until failure (GF). Information about the study and the training protocol were given at the moment to the participants, as well as the risks and benefits that the research would bring to the subjects. When they agreed, they signed the TCLE and, in sequence, were able to start the training protocols.

$2^{\text {nd }}$ Stage: Had the duration of 12 weeks with the training protocols for the two distinct groups. Both had 3 training sessions a week, respecting a minimum interval of 48 hours for a new session. The protocol relied only on the use of the bench press exercise for the work of pectorals. For GT, 10 series with $75 \%$ of $1 \mathrm{RM}$ were performed, with intervals of 80 seconds, seeking concentric fatigue. For GSF, the protocol was the same, however, a pre-exhaustive series was introduced before the protocol was started. This pre-exhaustive series counted on the accomplishment of a series of arms flexion in the soil also carried until the concentric failure.

$3^{\text {rd }}$ Stage: At the end of the 12-week protocol, the subjects were re-evaluated at $1 \mathrm{RM}$ and at muscle strength, as well as at the pre-protocol time. 
Maximum Repetition Protocol (1RM) and Strength Resistance

The 1RM protocol for the bench press consisted initially of heating 5 to 10 replicates at random loading, not exceeding $60 \%$ of $1 \mathrm{RM}$. After that, there was a 3-minute interval of passive interval, before inserting an initial load close to the maximum execution capacity of a repetition in the exercise. If the subject was able to perform more than one repetition, the protocol was interrupted, and the bar returned to the holder. After an interval of 5 minutes, weights of 2 to 10 kilograms ( 10\%) were added, performing the same previous process, until only one cycle of movement was performed (one repetition maximum). If the load of $1 \mathrm{RM}$ was found, the load was calculated for $50 \%$ of this value. The individual then sought to perform as many repetitions as possible with the stipulated weight. Both values (from 1RM to $50 \%$ of $1 \mathrm{RM}$ ) were used for the comparison data from the survey.

\section{Statistical Analysis}

The data of the two groups were tabulated in the preand post-training moments, the means were analyzed by the Student's T test, followed by the Smirnov-Kolmogorov test to obtain the level of significance between them. The value of $p$ $<0.05$ was adopted, and such analyzes were performed through the GraphPad Instat 3.1 software.

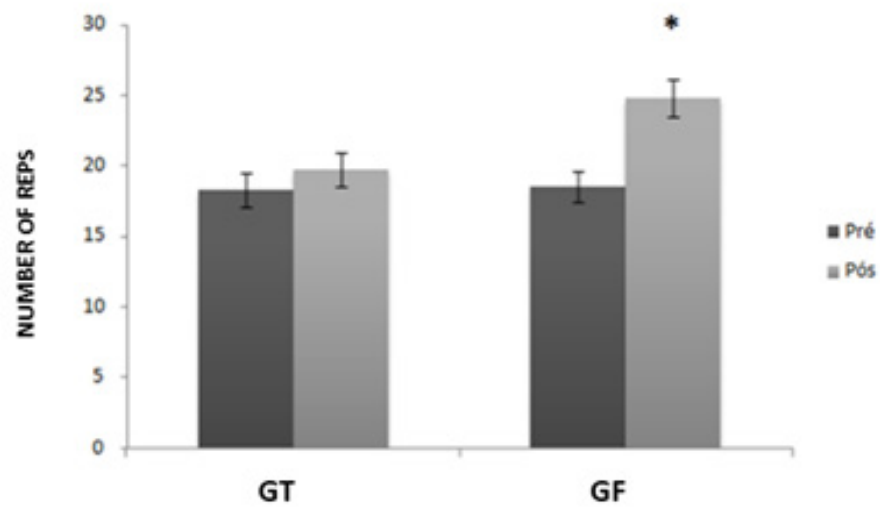

Figure 1: Analysis of means and comparisons between GT and GF groups pre and post intervention in relation to 1RM evaluation. ( statistically significant difference, $p<0.05$ ).

\section{Result}

After the data collected and analyzed, it was observed that the mean number of repetitions of the GF group (86.7 kg) was statistically significant in relation to the increase presented in the GT group (79.0 kg) after intervention on the training. These data are shown in (Figure 1). In relation to the maximum number of repetitions performed with a load of $50 \%$ of $1 \mathrm{RM}$, we also analyzed the means and verified the mathematical difference between pre and post intervention for both groups. It was verified that the GF group (24.8 rep) also obtained a better yield for this evaluated component, being statistically significant in relation to the GT group (18.5 rep). These data can be analyzed in (Figure 2).

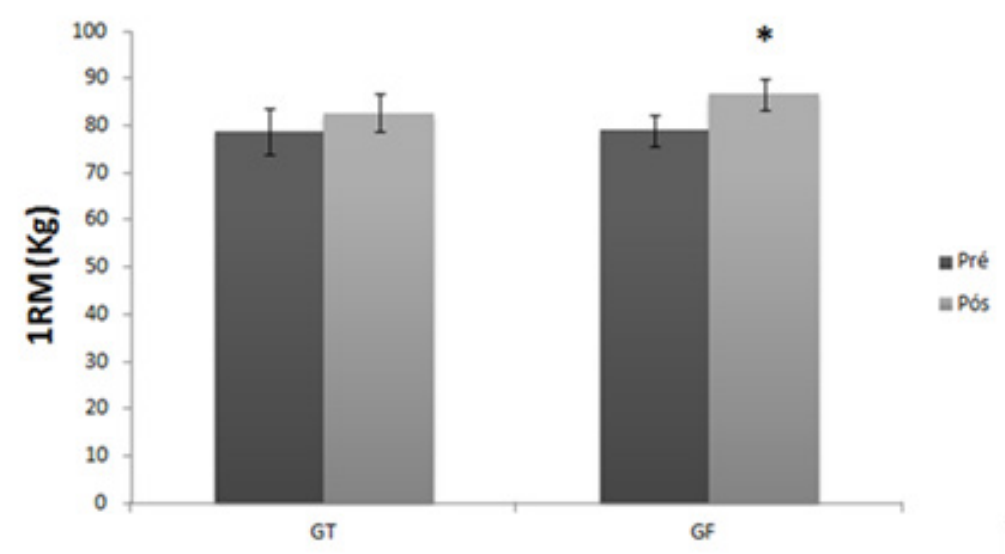

Figure 2: Analysis of the means between the GT and GF groups before and after intervention in relation to the evaluation of the number of maximal repetitions in $50 \%$ of 1 RM. ( ${ }^{*}$ statistically significant difference, $p=0.0001$ ). 


\section{Discussion}

This study observed that the sets of calisthenic exercise performed until muscular fatigue (flexion of arms in the ground), prior to the traditional training for pectorals, using the bench press, can be of great assistance for the development of muscular strength (1RM) and in the strength strength (maximum number of repetitions with $50 \%$ of $1 \mathrm{RM}$ ). This pre-exhaustion component adapted with a calisthenics exercise can be compared with other studies in the literature that used the traditional pre-exhaustion method and also obtained improvements in other parameters. And a study by Augustsson et al. [11] analyzed the effect of the pre-exhaustion method on the activation of the vastus lateralis, rectus femoris and gluteus maximus muscles during the leg press, where 17 trained men performed two sequences (with and without pre-exhaustion at random), with rest between them of twenty minutes, being a series of knee extension exhaustion pretension with 10 repetitions maximum (RM) in the extensor chair and a series of leg press also with the same load until the concentric fatigue. Afterwards, they performed only a series of leg presses with 10 RM load until the concentric failure. The analysis of the study was based on the number of repetitions and the surface electromyography method (painless technique that monitors and records the electrical activity of muscle fibers during contraction) of the rectus femoris and vastus lateralis muscles. There was a significant decrease in the electromyographic activity of these muscles after pre-exhaustion, and also that individuals performed fewer repetitions for the same load in the leg press when they did so after pre-exhaustion Tibana, Balsamo, Prestes [3]; pre-exhaustion within the training, assists in a more effective fatigue of the muscle group to be worked on during the session.

Another study carried out in 2007 by Gentil [12] submitted 13 subjects to bench press series with and without preexhaustion, performed through the crucifix exercise in the machine. The pectoralis major, anterior deltoid and triceps muscles were analyzed through number of repetitions and surface electromyography. A series of 10 RMs was performed at a rate of $2 \mathrm{~s}$ of concentric phase and $2 \mathrm{~s}$ of eccentric phase. Gentil [12] disprove the benefits of the pre-exhaustion method, since there was no increase in muscle activity of the major pectoralis and anterior deltoid, fatigued on the crucifix; and there was a significant reduction in total work performed in the multi-articular exercise after pre-exhaustion. The brachial triceps, not triggered in monoarticular exercise, presented increase in amplitude after the fatigue of the other muscles, indicating a greater number of motor units of this muscle in the performance of the bench press. It is important to emphasize that interventions and intra-sessional evaluations were not made during the execution of this research specifically, which does not allow such discussion in a more detailed way. The concern of the authors of this work was a macro context, observing significant differences after the intervention period, which was understood for 12 weeks.

The study of Bottaro [13], working with analysis in the lower limbs, sought to verify if the execution of a low intensity monoarticular exercise for the knee extensors would be efficient to increase the number of motor units recruited in the vastus lateralis muscle during the accomplishment of a subsequent multi-joint exercise. Training routines were performed with nine healthy male subjects, who performed the extensor chair and leg press exercises $45^{\circ}$ in sequence. In the low-intensity routine, 15 unilateral knee extensions were performed, followed by 15 repetitions of leg press $45^{\circ}$ with loads of $30 \%$ and $60 \%$ of a maximum repetition (1-RM), respectively. In the high-intensity routine (R60), the same sequence was performed, but the load of the two movements was $60 \%$ of 1-RM. A simple series of 15 repetitions leg press $45^{\circ}$ with $60 \%$ loading of 1 -RM was used as exercise control (RC). Surface electromyography was recorded in the vastus lateralis muscle through a linear array of electrodes. The RMS value was calculated for each repetition of the $45^{\circ}$ leg press. The data found in the electromyographic analysis showed that pre-exhaustion may be effective for better muscle activation, however, the authors emphasize that a more effective recruitment of motor units in the exercise routines was verified when the multi-articular exercise is preceded by monoarticular exercise. This factor highlights the pre-exhaustion component verified through the data of this work.

Júnior [14] sought to examine the effects of pre-exhaustive character exercises prior to local muscle resistance training (RML) on maximal dynamic strength and quadriceps muscle strength in young men. Twenty-seven healthy men who underwent (1RM), muscle endurance and magnetic resonance imaging at two different times (before and after an 8-week training program for RML in an extensor chair.) After the initial test, the subjects were divided into three groups: untrained control (CO, N. = 9), traditional training (TR, N. = 9) and previous exhaustive training (PE, N. $=9$ ). Both TR and PE groups trained using the same LME training protocol $(2 \mathrm{~d}$ week $-1 ; 3$ sets of $15-20$ repetitions at $50 \%$ of $1 \mathrm{RM}$ ) during the 8 week trial, the only difference was that the PE group performed an additional set of exhaustive exercises at $80 \%$ of $1 \mathrm{RM}$ immediately before each training session. After 8 weeks, it was observed that the PE group presented a greater increase $(\mathrm{P}<0.05)$ in $1 \mathrm{RM}$, resistance and work efficiency than the TR group. However, no change ( $P>0.05$ ) in the cross-sectional area (AST) and body mass were observed from pre-post-test in both groups. The authors report that the results show that the inclusion of a single preexhaustive exercise of up to $80 \%$ of $1 \mathrm{RM}$ immediately prior to LRM training may be a suitable strategy to induce additional beneficial effects on quadriceps strength and endurance in men young. These data from the literature demonstrate exactly what was found in this study, corroborating with the findings related 
to the improvement of the number of repetitions in $50 \%$ of $1 \mathrm{RM}$ and increase of the 1RM load [15].

\section{Conclusion}

The present study showed that a series of calisthenic exercises performed until fatigue, preceding traditional chest training using the bench press exercise, can be a good strategy to increase strength resistance (maximum number of repetitions with $50 \%$ of $1 \mathrm{RM}$ ) and at maximum 1RM force. However, some limitations of this research can be studied more thoroughly in another context of the literature, demonstrating more reliably such methodology and its effectiveness in muscle hypertrophy.

\section{References}

1. J Nunes, SM Rosa, FB Vecchio (2012) Treinamento de força com uso de correntes de potencialização pós ativação do salto vertical. Revista Brasileira de Ciência do Esporte, Florianópolis 34(7): 1017-1033.

2. D Rosa (2014) A influência da aplicação de exercícios de tríceps sobre an estimulação do peitoral no exercício supino reto - um estudo eletromiográfico. Rev. Bras. De Prescrição e Fisiologia do Exercício 8(44) 201-207.

3. RA Tibana, S Balsamo, J Prestes (2013) Pré-exaustão muscular Induzida por exercício monoarticular. Rev Bras Fisiologia do Exercício 12(4).

4. H Miguel, MVA Campos, RD Calixto, MTT Pacheco, (2018) Analysis of Acute Responses of Lactacidemy in Different Strength Training Methods in Trained Men. European Journal of Physical Education and Sport Science 4: 152-161.

5. H Miguel, MVA Campos, RD Calixto, MTT Pacheco, (2018) Resposta Aguda Do Lactato Sanguíneo Em Diferentes Métodos De Treinamento De Força Realizados Por Homens Treinados. Revista Brasileira De Prescrição E Fisiologia Do Exercício 12: 13-20.

6. DN Inácio (2016) No solo e na barra: memorial de filme sobre a prática de calistenia no DF. Centro Universitário de Brasília Uniceub. Brasília.
7. MC Bacarin (2012) Prescrição do treinamento de força a partir da força máxima (1RM) ou pelo método de repetições máximas: semelhanças, diferenças, vantagens e desvantagens. Rev Digital, Buenos Aires, Ano 17: 175 .

8. FP Caliani, KR Murata, MAG Rocha (2008) An Influência da fadiga neuromuscular diante de um treino excêntrico sobre o desempenho aeróbio. Unisalesiano, Lins/SP.

9. G Paz, Marianna de Freitas Maia, Felipe Luis dos Santos Santiago, Priscila Soares dos Santos, Vicente Pinheiro (2012) Efeitos imediatos da pré-atividade máxima dos antagonistas sobre a tensão isométrica máxima e sinal eletromiográfico. Rev. Bras. De Prescrição e Fisiologia do Exercício 6(32): 149-156.

10. MLS Geraldes (2013) Influência da pré-exaustão do grupo muscular bíceps braquial na execução do exercício de puxada alta dorsal. Dissertação (Mestrado em Ciências do Desporto). Universidade de Trás-os-Montes e Alto Douro. Vila Real.

11.J Augustsson, R Thomeé, P Hörnstedt, J Lindblom, J Karlsson, et al (2003) Effect of pre-exhaustion exercise on lower-extremity muscle activation during a leg press exercise. J Strength Cond Res 17(2): 411416.

12.P Gentil, E Oliveira, V Araújo Rocha Júnior, J Carmo, M Bottaro (2007) Effects of exercise order on upper-body muscle activation and exercise performance. J Strength Cond Res 21: 1082-1086.

13. VA Júnior, M Bottaro, MC Pereira, MMP Andrade, PR Júnior, et al. (2010) Electromyographic analyses of muscle pre-activation induced by single joint exercise. Rev Bras Fisioter, 14(2): 158-165.

14.VC Sanches (2014) Influência do exercício pré-exaustão sobre a resistência muscular durante treinamento resistido em homens jovens. Dissertação (Mestrado professional em exercício físico na promoção da saúde). Universidade Norte do Paraná Unopar. Londrina.

15. R Aguiar, VAR Júnior, Martim Bottaro, Maria CC Pereira, Marcelino M Andrade, et al. (2016) Análise eletromiográfica da pré-ativação muscular induzida por exercício monoarticular. Rev Bras Fisioterapia $1(2)$.

\section{Your next submission with Juniper Publishers} will reach you the below assets

- Quality Editorial service

- Swift Peer Review

- Reprints availability

- E-prints Service

- Manuscript Podcast for convenient understanding

- Global attainment for your research

- Manuscript accessibility in different formats

( Pdf, E-pub, Full Text, Audio)

- Unceasing customer service

Track the below URL for one-step submission

https://juniperpublishers.com/online-submission.php 